Case Report

\title{
Impacted inter-arytenoid chicken bone
}

\author{
Manish Munjal ${ }^{1 *}$, Shikha Gupta ${ }^{2}$, Tanvir Singh ${ }^{2}$, Porshia Rishi ${ }^{1}$, Harjnder Sidhu ${ }^{1}$, \\ Shubham Munjal ${ }^{3}$, Sivjot Binepal ${ }^{3}$
}

\begin{abstract}
${ }^{1}$ Department of ENT- Head and Neck Surgery, ${ }^{2}$ Department of Anaesthesia, ${ }^{3}$ Dayanand Medical College, Ludhiana, Punjab, India
\end{abstract}

Received: 24 July 2020

Revised: 06 September 2020

Accepted: 09 September 2020

\author{
*Correspondence: \\ Dr. Manish Munjal, \\ E-mail: manishmunjaldr@yahoo.com
}

Copyright: (C) the author(s), publisher and licensee Medip Academy. This is an open-access article distributed under the terms of the Creative Commons Attribution Non-Commercial License, which permits unrestricted non-commercial use. distribution. and reproduction in anv medium. provided the original work is properlv cited.

\begin{abstract}
The anebriated individual with sluggish reflexes is likely to aspirate inadverently fluids, semisolids and solids alike. Fish and chicken preparations with their sharp skeletal bones may lacerate or get entangled in the mucosa of the upper aerodigestive tract. The tonsillar fauces, pyriform fossae, post cricoid region, supraglottis, glottis, subglottis, trachea, carina and either bronchi are the common sites of impaction of sharp-edged foreign bodies. We herein present a case involving a 40-year-old patient who had aspirated a laryngotracheal foreign body (chicken bone) 3 days prior to hospital admission, which was removed by tracheostomy and suspension microlaryngoscopy.
\end{abstract}

Keywords: Interarytenoid, Chicken bone, Glottis, Laryngo- tracheoscopy, Tracheostomy

\section{INTRODUCTION}

Impaction of a foreign body in the larynx in adults is a rare occurrence as the studies analyzing adult patients have shown that a normal swallowing reflex protects against foreign body aspiration. Central nervous system disorders like stroke, loss of consciousness, metabolic encephalopathy, alcoholism, intellectual disability, psychiatric illness, seizure disorders, inhibition of the pharyngeal or cough reflex increase the menace of foreign body aspiration. ${ }^{1,2}$

The peak incidence of foreign body aspiration occurred during the second year of life in the child group and during the sixth decade in the adult group reported in the retrospective review of 20 years by Baharloo et al in $1999 .^{3}$

The common foreign bodies impacted are either organic (cotton, paper, seeds, wool or chicken bone) or Inorganic including metallic pieces, plastic, glass, chalk, rubber. ${ }^{4}$
A search of PubMed for "laryngeal foreign body chicken" revealed only six articles, of which only three were related to penetration syndrome. ${ }^{5}$ A rare case of inter-arytenoid foreign body is discussed.

\section{CASE REPORT}

A 40-year elderly male presented with an impacted foreign body in the oto- rhino-laryngology casualty services of a tertiary health care facility of north India. He presented with complaints of foreign body sensation and throat pain for 3 days. there was no complaint of stridor and dysphagia. There was prior history of manipulation which was futile. Imaging study (computed tomography) of the neck showed foreign body in the anterior glottis. Axial and saggital section of glottis (Figure 1 and 2).

He was taken up for rigid video laryngoscopy and extraction under short general anaesthesia (Figure 3). Though the foreign body was visualised in the interarytenoid region. 


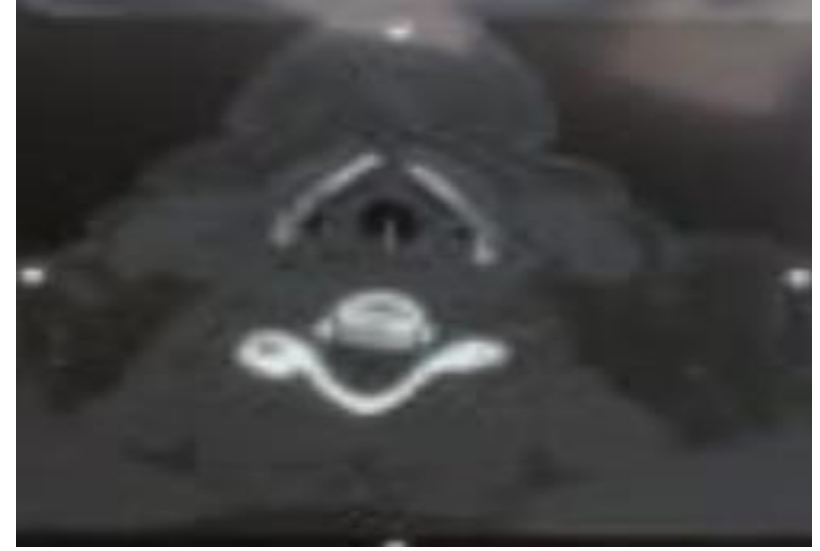

Figure 1: Axial section showing foreign body at the level of glottis.

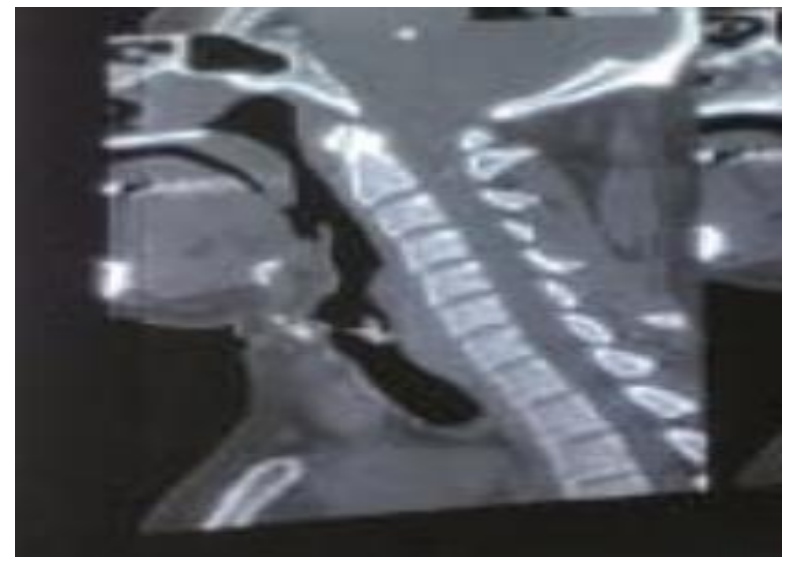

Figure 2: Saggital section showing foreign body in larynx.

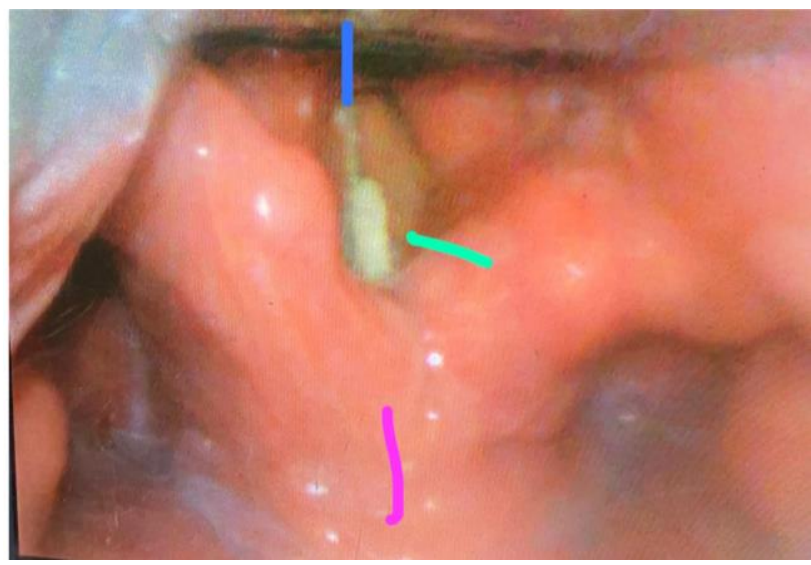

Figure 3: Videolaryngoscopic view chicken bone green, glottic chink blue, interarytenoid region pink.

It could not be extracted with the alligator forceps. Further manipulation dislodged it, and it got entangled just below the posterior commissure. At this subglottic location, endotracheal intubation was difficult and with a likelihood of a lower tracheal migration or a transtracheal penetration. A mid-level tracheostomy was performed to facilitate protection of the lower trachea and administer inhalational anaesthesia. Under full long acting muscle relaxation using atracurium (Figure 4). Laryngo-tracheoscopy was undertaken and the chicken bone extracted (Figure 5).

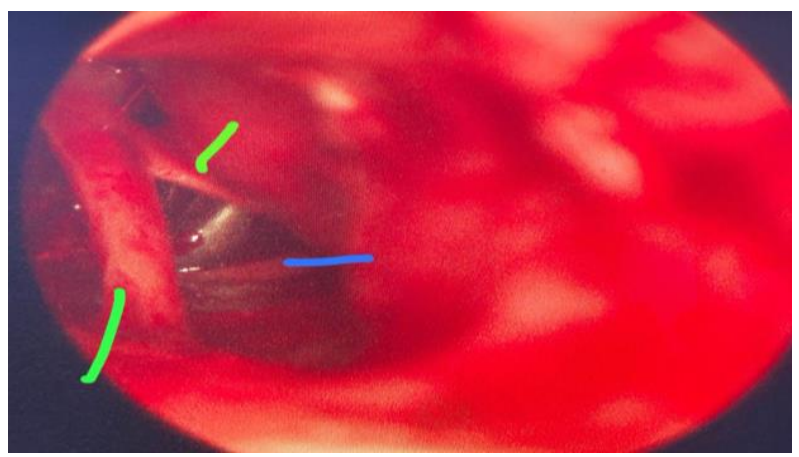

Figure 4: foreign body (chicken bone- green) when dislodged below in glottis (blue).

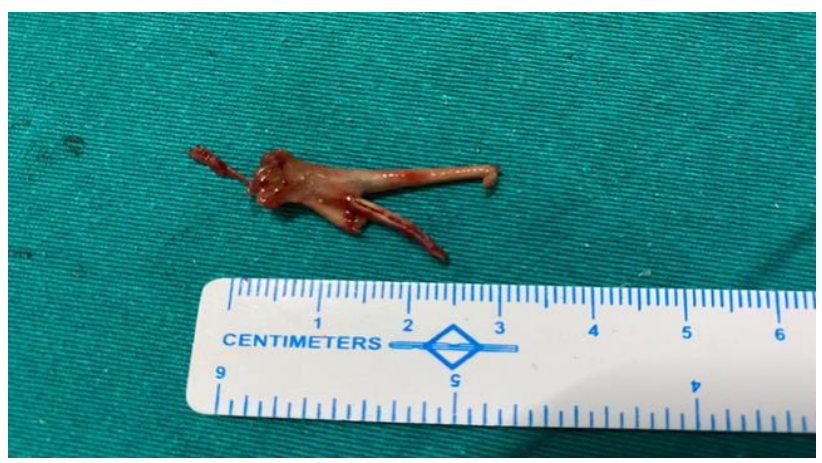

Figure 5: Extracted foreign body (chicken bone).

Post-operative phase was uneventful. The vocal cords were mobile but the laryngeal inlet was oedematous, for which injectable dexamethasone was administered for 3 days. He was decannulated on day 3 and thereby relieved from the health care facility.

\section{DISCUSSION}

Clinical presentation of foreign body aspiration can range from chronic nonspecific throat pain and foreign body sensation to severe respiratory complaints such as dyspnoea, drooling, stridor, and cyanosis .These symptoms, known as the penetration syndrome, occur in half of patients aspirating and include a choking sensation accompanied by respiratory distress with coughing, wheezing, and dyspnea. ${ }^{6}$

The longest duration of a chronic foreign body in the airway was reported by Weisberg and Schwartz in 1987 where they reported a chicken breast bone lodged in the bronchus intermedius for 12 years which was later retrieved by bronchotomy.

The nature, size, location, and time of aspiration of the laryngeal foreign bodies decide the presenting complaints. ${ }^{8}$ 
In 1968 Shigeto Ikeda introduced flexible endoscopy and revolutionized the management of laryngeal foreign bodies. $^{9}$

Careful clinical history-taking and physical examination is necessary for prompt diagnosis. Endoscopic examination of the larynx, trachea, and lungs is used to visualize and thus aids in removal of laryngeal foreign bodies. $^{10}$

In our patient the laryngeal foreign body was extracted by suspension microlaryngoscopy under general anesthesia after tracheostomy for ventilation.

Similar removal of chicken bone foreign body is reported by Balica et al in 2019 in 78-year-old patient with congenital intellectual disability. ${ }^{11}$

Laryngeal edema is the commonest sequelae after laryngeal foreign body removal, as in our case too which responded to corticosteroids. Bleeding can occur due to granulation tissue or erosion into a major vessel. An airway tear can cause pneumothorax and pneumome diastinum. $^{11}$

\section{CONCLUSION}

Laryngeal foreign body aspiration is an emergency, and rapid identification and thus removal will reduce morbidity and mortality. High index of suspicion with adequate radiological and endoscopic evaluation is a must before embarking on a management protocol.

Funding: No funding sources Conflict of interest: None declared

Ethical approval: Not required

\section{REFERENCES}

1. Boyd M, Chatterjee A, Chiles C, Chin R Jr. Tracheobronchial foreign body aspiration in adults. South Med J. 2009;102(2):171-4.
2. He B, Huang Y, Li Q, Dai J, Yuan X. Diagnosis of children with occult bronchial foreign body. Chine $\mathrm{J}$ Pediatri. 2014;52(11):851-3.

3. Baharloo F, Veyckemans F, Francis C, Biettlot MP, Rodenstein DO. Tracheobronchial foreign bodies: presentation and management in children and adults. Chest. 1999;115(5): 1357-62.

4. Archana B. A study on upper aerodigestive tract foreign bodies. Doctoral dissertation, Madras Medical College, Chennai.

5. Balica NC, Sitaru AM, Boia ER, Horhat DI, Mot IC, Chioreanu A, et al. Laryngotracheal foreign body: chicken neck bone. J Int Med Resea. 2019;47(6): 2764-7.

6. Hoeve LJ Rambout J, Pot DJ. Foreign body aspiration in children. The diagnostic value of signs symptoms and preop examination. Clinic Otolaryn Alli Sscien. 1993;18(1)55-7.

7. Weissberg D, Schwartz I. Foreign bodies in the tracheobronchial tree. Ches. 1987;(5): 730-3.

8. Doust BD, Ting YM, Chuang VP. Detection of aspirated foreign bodies with xeroradiography. Radiology. 1974;111(3):725-7.

9. Hada MS, Samdhani S, Chadha V, Harshvardhan RS, Prakash M. Laryngeal foreign bodies among adults. J Broncho Interventi Pulmono. 2015;22(2): 145-7.

10. Timbo, SK, Keita, MA, Doumbia-Singare, K. Medical handicap and otorhinolaryngologic foreign bodies about 4 original cases. Mali Med. 2010;25:50-5.

11. Balica NC, Sitaru AM, Boia ER, Horhat DI, Mot IC, Chioreanu A, et al. Laryngotracheal foreign body: chicken neck bone. Journal of International Medical Research. 2019;47(6):2764-7.

Cite this article as: Munjal M, Gupta S, Singh T, Rishi P, Sidhu H, Munjal S. Impacted inter-arytenoid chicken bone. Int J Otorhinolaryngol Head Neck Surg 2020;6:1894-6. 